\title{
Avaliação da Influência de Tratamentos Térmicos Pós-Soldagem Sobre a Microestrutura e Propriedades Mecânicas de Juntas de um Aço API 5 L X70Q
}

\author{
Lívia Carla Silva de Araújo ${ }^{1}$, Luiz Cláudio Cândido ${ }^{1}$, Vicente Braz Trindade ${ }^{1}$, Rodrigo Rangel Porcaro² \\ 1 Rede Temática em Engenharia de Materiais - REDEMAT, Universidade Federal de Ouro Preto - UFOP, Ouro Preto, MG, Brasil. \\ 2 Instituto Federal de Minas Gerais - IFMG, Ouro Branco, MG, Brasil.
}

Recebido: 07 Abr., 2015

Aceito: 10 Jun., 2015.

E-mail: rodrigo.porcaro@ifmg.edu.br (RPP)
Resumo: Aços que atendem à norma API 5L são aplicados na construção de dutos e há grande interesse naqueles de maior resistência, como o grau API $5 \mathrm{~L} X 70 \mathrm{Q}$. Ainda são escassos os estudos relacionados a tubos sem costura. Durante a montagem, os tubos podem ser soldados por eletrodos revestidos (SMAW) e eventualmente sofrer aquecimento indutivo para adequação à topografia do terreno, processos que podem alterar a microestrutura das juntas. Neste trabalho foram obtidas juntas soldadas pelo processo SMAW, a partir de tubo sem costura grau API 5L X70Q. As juntas foram submetidas a tratamentos térmicos pós-soldagem nas temperaturas $920{ }^{\circ} \mathrm{C}$ e $600{ }^{\circ} \mathrm{C}$. Foram realizados ensaios de tração, impacto Charpy e microdureza, além de caracterização metalográfica nas amostras de metal base e nas juntas como soldadas e após os tratamentos térmicos. O tratamento térmico a $920^{\circ} \mathrm{C}$ promoveu a formação de estrutura ferrita/perlita, com consequente redução na resistência mecânica das juntas a valores inferiores aos especificados para o grau X70Q. Porém, o tratamento térmico a $600{ }^{\circ} \mathrm{C}$ mostrou-se benéfico devido à redução da fração volumétrica dos constituintes martensita/austenita e martensita-austenita-bainita, sem reduzir de forma significativa a resistência mecânica e com relativo ganho na tenacidade ao impacto na ZTA e na ZF.

Palavras-chave: Aços ao Carbono e aços de baixa liga; Metalurgia da soldagem; Propriedades Mecânicas de juntas soldadas.

\section{Evaluation of the Influence of Post Welding Heat Treatments on Microstructure and Mechanical Properties of API 5L X70Q Weld Joints}

\begin{abstract}
Pipelines for oil and gas conduction are manufactured of steel tubes that meet the API $5 \mathrm{~L}$ requirements. Currently, much of the research related to the materials used in

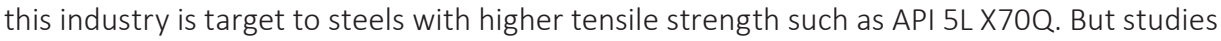
related to seamless pipes remains rare. During the manufacture of the pipelines, the pipes are usually welded by the SMAW process and may be heated by the inducted bending process to fit the topography of the land, processes that can change the proportion or morphology of the constituents in the heat affected zone (HAZ) and in the fused metal. The present study used an API $5 \mathrm{~L} X 70 Q$ seamless steel manufactured by the Mannesmann Process to produce weld joints by the SMAW process. The joints were subjected to post weld heat treatments in the temperatures of $920^{\circ} \mathrm{C}$ and $600{ }^{\circ} \mathrm{C}$. Mechanical tests which included tensile test, Charpy impact and microhardness were applied, in addition to microstructure evaluation in the joints as welded and after heat treatments. The results showed that the first heat treatment $\left(920^{\circ} \mathrm{C}\right.$ ) promoted the formation of structure ferrite/pearlite, which reduced the mechanical properties to values under the specified for materials API grade $X 70 Q$. The second heat treatment $\left(600^{\circ} \mathrm{C}\right)$ was feasible in reducing the volume fraction of the Martensite-Austenite and Martensite-Austenite-Bainite constituents, without significant reduction in mechanical strength of the welded joints and with significant gain in impact toughness in the HAZ and in the weld metal.
\end{abstract}

Key-words: Carbon and low alloy steels; Welding metallurgy; Mechanical properties of welded joints.

\section{Introdução}

Atualmente, grande parte das pesquisas relacionadas aos materiais utilizados na confecção de dutos está direcionada a graus de aços de maior valor de limite de resistência, como o grau API 5L X70Q [1]. Mas ainda são escassos os estudos relacionados a tubos sem costura, uma técnica bastante moderna e complexa para a produção de tubos laminados a quente, seguido ou não de tratamento térmico. O aço que atende ao grau API 5L X70Q, 
apresenta estrutura composta por martensita revenida, que por sua vez, sofre alterações estruturais durante o processo de soldagem, especialmente na zona termicamente afetada (ZTA) devido aos ciclos térmicos impostos por múltiplos passes [2].

Na montagem de dutos, os tubos podem ser soldados pelo processo eletrodos revestidos (SMAW) e ainda podem sofrer aquecimento indutivo para curvamento e adequação à topografia do terreno. Durante o curvamento a quente, as juntas soldadas são submetidas a temperaturas que podem ultrapassar $1000^{\circ} \mathrm{C}$, por mais de 2 min [3,4]. A parte curvada do tubo e as extremidades retas podem sofrer um tratamento posterior ao curvamento a quente para alcançar propriedades mecânicas desejáveis. Assim, pode ocorrer formação de novas estruturas ou alteração da fração volumétrica de fases/constituintes como ferrita acicular, bainita, ferrita poligonal, ferrita de Widmanstätten, constituinte martensita/austenita (M-A) disperso na forma de ilhas e agregados ferrita-carbonetos [5].

Este estudo avaliou a influência das temperaturas empregadas em tratamentos térmicos nas propriedades mecânicas e estrutura de tubos sem costura API 5L X70Q, utilizados na construção de dutos e soldados pelo processo eletrodos revestidos. O objetivo foi induzir a formação de diferentes microestruturas e realizar a sua caracterização, de modo a avaliar se tais tratamentos térmicos seriam ou não adequados para uma relação ótima entre microestrutura e propriedades.

\section{Materiais e Métodos}

O metal base foi extraído na forma de arcos, a partir de tubos sem costura no estado laminado com diâmetro externo igual a $406,4 \mathrm{~mm}$ e espessura igual a 9,5 $\mathrm{mm}$. Realizaram-se tratamentos térmicos de têmpera, com austenitização a $920^{\circ} \mathrm{C}$ por 20 min e resfriamento em água a $27^{\circ} \mathrm{C}$ com agitação, seguido de revenimento a $490{ }^{\circ} \mathrm{C}$ por 30 min, de modo a atender às especificações do grau API $5 \mathrm{~L}$ X70Q. Em seguida, os arcos foram preparados com a confecção de chanfro em V, com dimensões recomendadas pela norma API 1104 [6] e soldadas pelo processo SMAW, com utilização do eletrodo celulósico ASME SFA5.1 E-6010 para o passe de raiz e, para os passes de enchimento e acabamento, um eletrodo celulósico ASME SFA5.5 9010-G. Os principais parâmetros de soldagem são apresentados na Tabela 1. Para garantir penetração completa na raiz das juntas, foi realizado um passe de reforço, aplicado após remoção de excesso de material do passe de raiz com eletrodo ASME SFA5.5 9010-G.

Foram realizados ainda dois tratamentos térmicos distintos nas juntas soldadas: (i) normalização $920^{\circ} \mathrm{C} / 20$ minutos (CS-N) e (ii) revenimento a $600^{\circ} \mathrm{C}$ durante 1 hora $\left(\mathrm{CS}-600^{\circ} \mathrm{C}\right.$ ). Para fins comparativos, o metal base foi submetido aos mesmos tratamentos térmicos.

Foi utilizado reagente Le Pera para análise microestrutural por microscopia óptica e eletrônica de varredura, com objetivo de avaliar qualitativamente os constituintes M-A e agregados ferrita carboneto.

Metalografia quantitativa foi realizada no material como soldado (CS) e após tratamento térmico pós-soldagem a $600^{\circ} \mathrm{C}\left(\mathrm{CS}-600^{\circ} \mathrm{C}\right)$. A contagem dos constituintes foi realizada na região com $100 \%$ dos grãos colunares (passe de

Tabela 1. Parâmetros de soldagem utilizados.

\begin{tabular}{|c|c|c|c|c|}
\hline \multicolumn{5}{|c|}{ METAIS DE ADIÇÃO } \\
\hline \multicolumn{2}{|c|}{ Passes } & Raiz & Enchimento & $\begin{array}{l}\text { Acabamento e passe de } \\
\text { reforço }\end{array}$ \\
\hline \multicolumn{2}{|c|}{ Classificação AWS } & A 5.1 E 6010 & A 5.5 E 9010 & A 5.5 E 9010 \\
\hline \multicolumn{2}{|c|}{ Polaridade/Tipo de corrente } & $\mathrm{CC}+$ & $\mathrm{CC}+$ & $\mathrm{CC}+$ \\
\hline \multicolumn{2}{|c|}{ Posição de Soldagem } & Plana & Plana & Plana \\
\hline \multirow[b]{2}{*}{ Passes } & & PARÂMETRC & & \\
\hline & $\begin{array}{l}\text { Diâmetro (eletrodo) } \\
\text { (mm) }\end{array}$ & $\begin{array}{l}\text { Corrente } \\
\text { (A) }\end{array}$ & $\begin{array}{l}\text { Tensão } \\
\text { (V) }\end{array}$ & $\begin{array}{l}\text { Velocidade de Soldagem } \\
\qquad(\mathrm{mm} / \mathrm{s})\end{array}$ \\
\hline Raiz & 2,00 & 77 & 29 & 1,45 \\
\hline Enchimento & 3,25 & 90 & 29 & 1,50 \\
\hline Acabamento & 3,25 & 90 & 29 & 1,50 \\
\hline Reforço & 3,25 & 90 & 29 & 1,50 \\
\hline
\end{tabular}


acabamento), pela aquisição de imagens com aumento de 500x, utilizando ataque nital $5 \%$, em quarenta diferentes campos aleatórios, em uma malha de 100 pontos (totalizando 4000 pontos), conforme Norma ASTM E562 [7].

Para avaliação das propriedades mecânicas, realizou-se ensaio de tração para as condições CS, CS-N e CS- $600{ }^{\circ} \mathrm{C}$ e ensaio de impacto Charpy para as condições CS, CS-N e CS- $600{ }^{\circ} \mathrm{C}$, com entalhes na Zona Fundida e ZTA, todos os ensaios segundo as normas ASTM A370 [8] e API 5L [1]. Avaliou-se também a microdureza Vickers para as condições $\mathrm{CS}$, CS-N e CS-600 ${ }^{\circ} \mathrm{C}$, com carga igual a $25 \mathrm{gf}$, no passe de acabamento.

Foi realizada análise química do metal base e do cordão de solda utilizando espectrometria por emissão óptica. Na Figura 1 apresenta-se uma seção transversal esquemática do cordão de solda com a indicação da posição da análise química, ensaios de impacto Charpy e microdureza Vickers.

\section{Resultados e Discussão}

Os resultados da análise química do metal base atenderam à especificação para o material X70Q, para o nível de qualidade PSL2, conforme Norma API 5L [1]. Os resultados de análise química do metal de solda são apresentados na Tabela 2.

Fotomicrografias do metal base antes e após os tratamentos térmicos de têmpera e revenimento são apresentadas na Figura 2. Observa-se que os tratamentos térmicos aplicados promoveram significativo refino de grão na estrutura do aço.

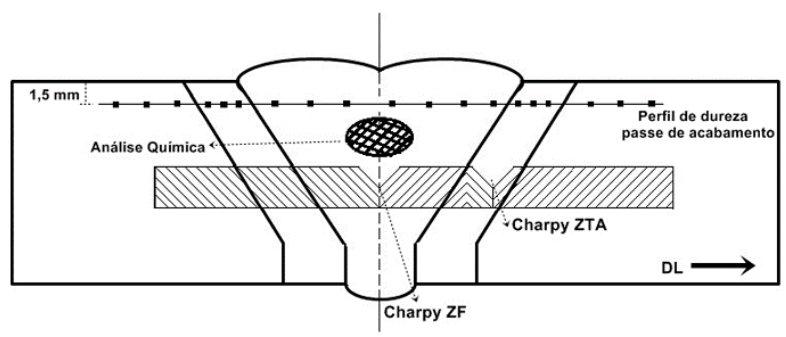

Figura 1. Representação esquemática de seção transversal de cordão de solda indicando as posições dos ensaios de impacto Charpy, análise química e perfil de microdureza Vickers. DL - direção de laminação.
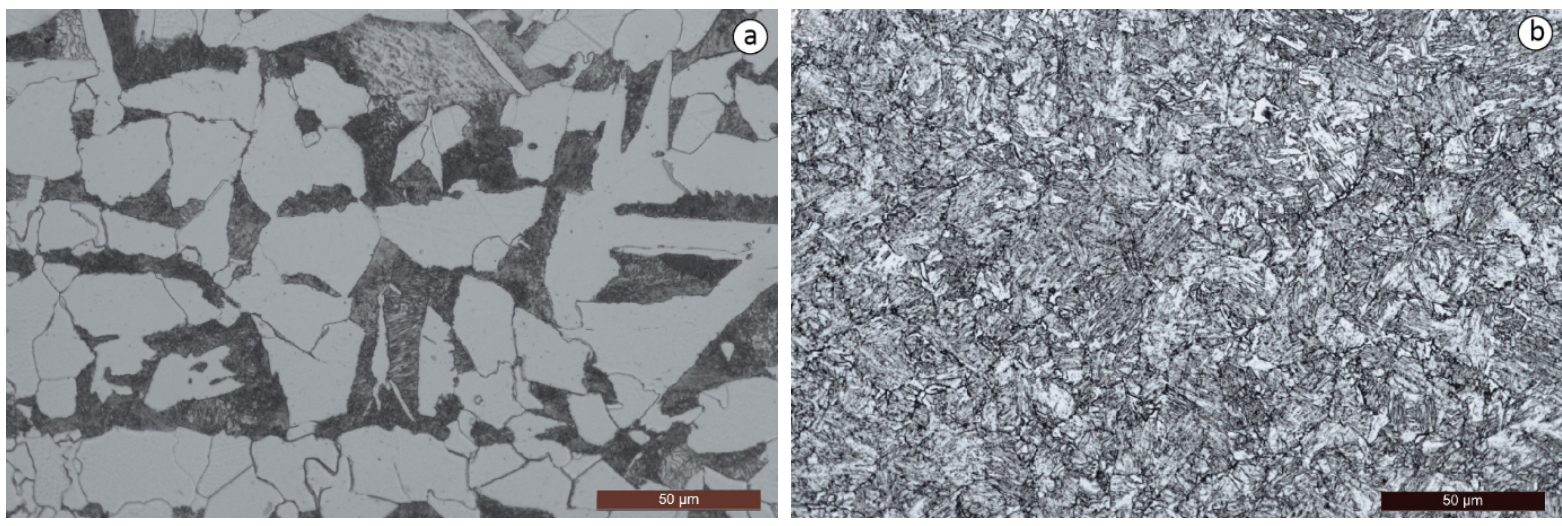

Figura 2. Metalografia óptica: (a) Metal Base no estado laminado, 500x. (b) Metal Base após tratamento de têmpera e revenimento, 500x. Ataque Nital 5\%.

Tabela 2. Composição química do metal de solda.

\begin{tabular}{cccccccc}
\hline \multicolumn{7}{c}{ Análise Química do Cordão de Solda (\% em massa) } \\
$\mathrm{C}$ & $\mathrm{Mn}$ & $\mathrm{P}$ & $\mathrm{S}$ & $\mathrm{Si}$ & $\mathrm{Ni}$ & $\mathrm{Cr}$ & $\mathrm{Cu}$ \\
0,148 & 0,781 & 0,014 & 0,008 & 0,298 & 0,031 & 0,062 & 0,036 \\
$\mathrm{Mo}$ & $\mathrm{V}$ & $\mathrm{Nb}$ & $\mathrm{B}$ & $\mathrm{Ti}$ & $\mathrm{C}$ & & \\
0,02 & 0,003 & 0,0016 & 0,0002 & 0,0167 & 0,30 & & \\
\hline
\end{tabular}

$\mathrm{C}_{\text {eq }}$ - carbono equivalente segundo o IIW. 
$\mathrm{Na}$ Figura 3 são apresentadas fotomicrografias obtidas por microscopia óptica do metal de solda nas condições como soldado (CS), como soldado e normalizado (CS-N) e como soldado e tratado a $600{ }^{\circ} \mathrm{C}\left(\mathrm{CS}-600^{\circ} \mathrm{C}\right)$, além da ZTA após o tratamento térmico a $600{ }^{\circ} \mathrm{C}$, ataque com regente Le Pera.

No presente trabalho, o reagente Le Pera foi utilizado para uma avaliação qualitativa da presença do constituinte M-A. Pode-se observar a partir da Figura 3 que o metal de solda na condição como soldado (Figura 3a) e como soldado e normalizado (Figura $3 \mathrm{~b}$ ) apresentou pontos brancos que podem corresponder a constituinte M-A e/ou agregado ferrita carboneto. No entanto, após o tratamento térmico a $600{ }^{\circ} \mathrm{C}$, observa-se uma redução significativa das regiões não atacadas (brancas) tanto na Zona Fundida (Figura 3c) quanto na Zona Termicamente Afetada (Figura 3d). Laitinen [9] obteve resultados semelhantes ao tratar a $600^{\circ} \mathrm{C}$, durante 4 horas, a ZTA de um aço de alta resistência mecânica e baixa liga.

As juntas soldadas em todas as condições (CS, CS-N e CS-600 ㄷ) e após o ataque Le Pera, foram analisadas em MEV para diferenciar o constituinte M-A de outras microfases presentes, como pode ser observado na Figura 4, Figura 5 e Figura 6.

Similarmente ao obtido por Trindade et al. [5], após o tratamento térmico de normalização, formou-se no metal de solda um agregado de martensita/austenita retida/bainita (M-A-B), apresentando região descontínua (bainita) e região contínua (M-A), a região de transição entre estas duas regiões é representada pela linha na Figura 4.

O tratamento térmico a $600{ }^{\circ} \mathrm{C}$ promoveu significativa redução na proporção de constituinte $\mathrm{M}-\mathrm{A}$ e/ou agregados ferrita-carbonetos que são revelados pelo ataque Le Pera (Figura 5), corroborando os resultados obtidos por microscopia óptica.
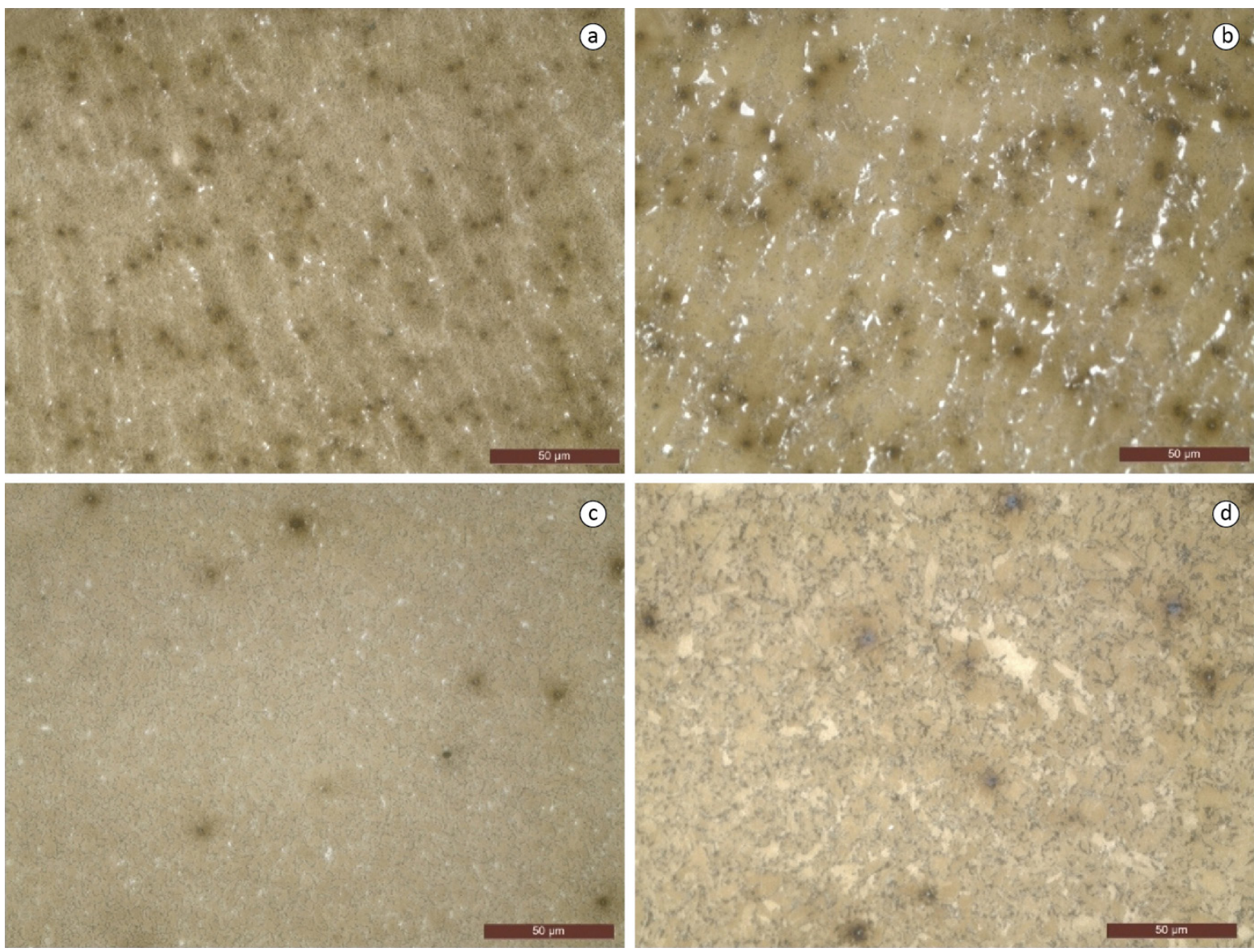

Figura 3. Metalografia óptica: (a) Zona Fundida (passe de enchimento) do material como soldado, 500x. (b) Zona Fundida do material soldado e normalizado, 500x. (c) Zona Fundida (passe de enchimento) do material soldado e tratado a $600{ }^{\circ} \mathrm{C}, 500 x$. (d) Zona Termicamente Afetada do material soldado e tratado a $600{ }^{\circ} \mathrm{C}, 500 \mathrm{x}$. Ataque Le Pera. 


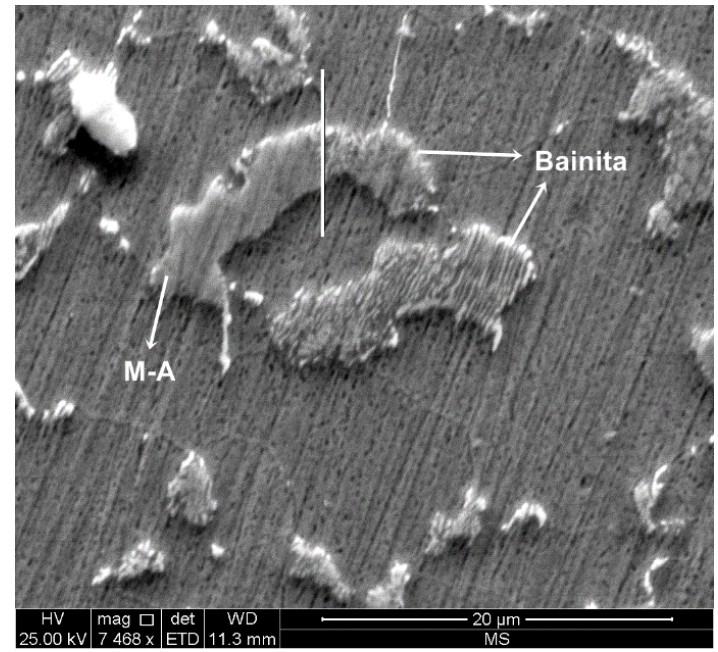

Figura 4. Zona fundida do material soldado e submetido a tratamento térmico de normalização, em destaque a região de transição entre a região descontínua (bainita) e contínua (agregado M-A). Ataque Le Pera, MEV, 7468x.
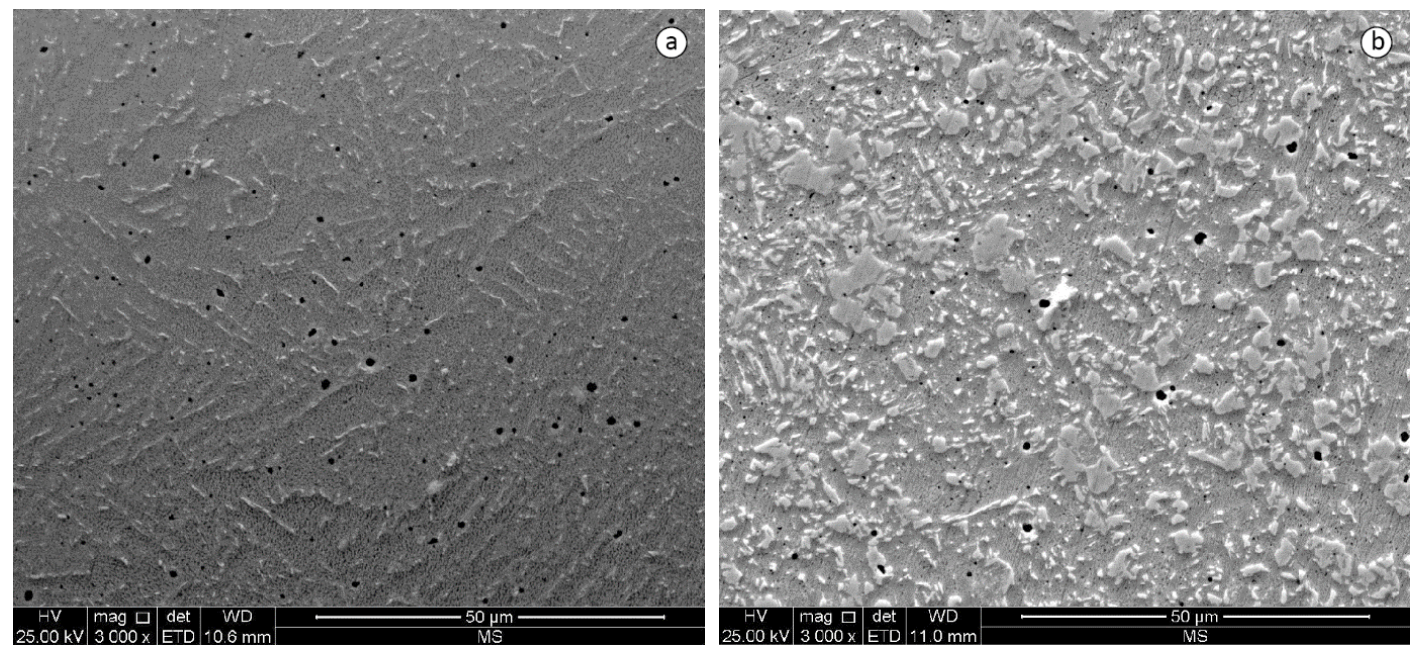

Figura 5. Zona fundida: (a) material soldado e submetido a tratamento a $600^{\circ} \mathrm{C}$; (b) material como soldado. Ataque Le Pera, MEV, 3000x.
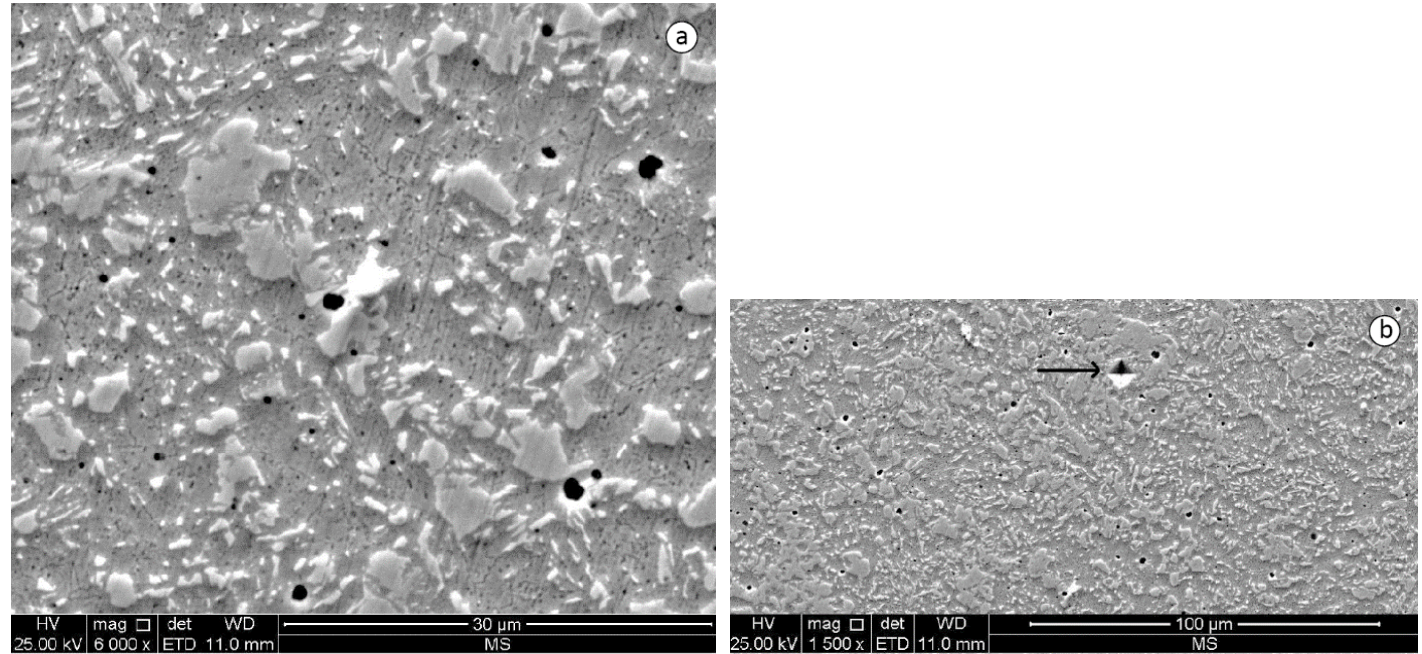

Figura 6. Zona fundida na condição como soldado: (a) 6000x; (b) destaque para indentação de microdureza próxima a um constituinte não atacado pelo reagente Le Pera, 1500x. Ataque Le Pera, MEV. 
A fim de confirmar que as microestruturas observadas sob microscopia óptica após o ataque Le Pera tratavam-se de M-A (Figura 3a), foram realizadas indentações de microdureza Vickers em algumas destas regiões. Em seguida, a amostra foi analisada em MEV, confirmando que as indentações foram realizadas próximas aos constituintes revelados por ataque Le Pera, conforme Figura $6 \mathrm{~b}$. Os valores de microdureza encontrados, Tabela 3 , correspondem a valores de dureza de constituintes M-A, como relatado por Hrivnak et al. [10]. A microestrutura pode então ser considerada como:

- Região atacada corresponde à ferrita;

- Região não atacada: constituintes contínuos e de maior tamanho relativo equivalem a M-A e constituintes de menor tamanho relativo e mais claros, correspondem a Agregados Ferrita Carbonetos.

A distinção entre os micro constituintes M-A e Agregados Ferrita Carbonetos (FC), não atacados pelo reagente Le Pera, só é possível por microscopia eletrônica de varredura.

Os resultados obtidos na metalografia quantitativa estão apresentados na Tabela 4, que ilustra a distribuição dos constituintes analisados na zona fundida na condição como soldado (CS) e após o tratamento térmico a $600{ }^{\circ} \mathrm{C}$ $\left(\mathrm{CS}-600^{\circ} \mathrm{C}\right)$.

Observa-se a partir da Tabela 4 grande proporção de ferrita primária $(52,1 \%)$ e apenas $35 \%$ de ferrita acicular na condição CS. Trindade et al. [5] obtiveram resultados semelhantes ao soldar um aço de alta resistência mecânica e baixa liga pelo processo arco submerso, obtendo um metal de solda com composição química semelhante ao observado no presente trabalho.

Observou-se também que o tratamento térmico a $600^{\circ} \mathrm{C}$ promoveu uma redução na proporção de constituintes classificados como ferrita acicular (FA) e aumento dos constituintes identificados como ferrita carbonetos (FC), segundo a metodologia proposta pelo IIW (Instituto Internacional de Soldagem), Colpaert [11]. O incremento de FC após o tratamento térmico a $600^{\circ} \mathrm{C}$ pode ser atribuído à decomposição do constituinte $\mathrm{M}-\mathrm{A}$ em ferrita-carbonetos.

\subsection{Propriedades mecânicas}

Os valores obtidos nos perfis de microdureza Vickers do passe de acabamento estão apresentados na Figura 7 , nas condições como soldado (CS), após os tratamentos térmicos de normalização (CS-N) e a $600{ }^{\circ} \mathrm{C}\left(\mathrm{CS}-600{ }^{\circ} \mathrm{C}\right)$. Pode-se notar que a microdureza nas regiões de metal base, ZTA e zona fundida, apresentou redução com os tratamentos térmicos pós-soldagem. Este resultado foi coerente com as mudanças microestruturais reveladas pela metalografia, ou seja, o tratamento térmico de normalização resultou em uma microestrutura composta por grãos equiaxiais e recristalizados de ferrita/perlita, justificando a menor dureza obtida para essa condição.

Observa-se que os valores de microdureza da zona fundida na condição soldada e normalizada (CS-N na Figura 7) apresentaram grande variabilidade, resultado que sugere que indentações foram realizadas em regiões próximas a constituintes $\mathrm{M}-\mathrm{A}-\mathrm{B}$ revelados na análise metalográfica.

Tabela 3. Valores de dureza de indentações realizadas próximas de constituintes M-A por microdureza Vickers, passe de acabamento.

\begin{tabular}{|c|c|c|c|c|c|c|c|c|c|c|}
\hline \multicolumn{8}{|c|}{ Microdureza Vickers constituinte M-A (HV) } & \multirow{2}{*}{$\begin{array}{c}\text { Média } \\
443\end{array}$} & \multirow{2}{*}{$\begin{array}{c}\text { Desvio } \\
\text { padrão } \\
\pm 31\end{array}$} & \multirow{2}{*}{$\begin{array}{c}\text { Carga } \\
\text { aplicada } \\
25 \mathrm{gf}\end{array}$} \\
\hline 425 & 453 & 412 & 446 & 463 & 502 & 441 & 404 & & & \\
\hline
\end{tabular}

Tabela 4.Porcentagem de constituintes presentes na zona fundida na condição como soldado (CS) e com tratamento pós-soldagem $\left(\mathrm{CS}-600^{\circ} \mathrm{C}\right)$.

\begin{tabular}{cccccc}
\hline & FA & FP & FS & FS(A) & FC \\
$\mathrm{CS}$ & 35,0 & 52,1 & 3,1 & 0,4 & 9,4 \\
$\mathrm{CS}-600^{\circ} \mathrm{C}$ & 24,0 & 55,0 & 4,0 & 0,0 & 17,0 \\
\hline
\end{tabular}

FA - Ferrita acicular; FP - Ferrita primária; FS - Ferrita com segunda fase; FS(A) - Ferrita com segunda fase alinhada; FC - Agregado ferrita e carbonetos 


\subsection{Ensaio de tração}

Os resultados obtidos nos ensaios de tração para as diversas condições estudadas, além do metal base, são apresentados na Figura 8, ressalta-se que em juntas soldadas não são avaliados o limite de escoamento e o alongamento [1]. O material na condição como soldado (CS) atendeu aos requisitos mínimos de limite de resistência para o grau X70Q. Após o tratamento térmico de normalização, as juntas soldadas (CS-N) tiveram queda nos valores de resistência mecânica à tração, atendendo ao grau X46. Já com o tratamento a $600{ }^{\circ} \mathrm{C}\left(\mathrm{CS}-600{ }^{\circ} \mathrm{C}\right)$, o material apresentou queda nos valores de limite de resistência, mas continuou atendendo ao mínimo especificado para o grau X70Q.

\subsection{Ensaio de impacto charpy}

Os resultados de energia absorvida em corpos de prova Charpy com entalhe na zona fundida são apresentados na Figura 9 e, para fins de comparação, apresentam-se também os resultados do metal base. $O$ requisito mínimo para a norma API $5 \mathrm{~L}$ é a absorção de $27 \mathrm{~J} \mathrm{a} 0{ }^{\circ} \mathrm{C}$, portanto, todas as condições atenderam ao grau $\mathrm{X70Q}$. Percebe-se que os tratamentos térmicos pós-soldagem exerceram pequena influência na energia absorvida nas temperaturas de $-50{ }^{\circ} \mathrm{C} \mathrm{e}-20^{\circ} \mathrm{C}$. Para a temperatura igual a $0{ }^{\circ} \mathrm{C}$, a energia média absorvida aumentou em aproximadamente $90 \%$ após o tratamento térmico de normalização e $30 \%$ após o tratamento térmico a $600^{\circ} \mathrm{C}$.

De modo geral, mesmo com os tratamentos térmicos pós-soldagem, a zona fundida apresentou baixa absorção de energia quando comparada ao metal base. Esse comportamento está relacionado à pequena proporção de ferrita acicular nesta região e presença de M-A e FC, como revelado pela metalografia quantitativa (Tabela 4) e análise em MEV (Figura 5 e Figura 6). Trindade et al. [5] obtiveram resultados semelhantes ao soldar um aço de alta resistência mecânica e baixa liga pelo processo arco submerso. Os autores avaliaram o efeito do tratamento térmico de normalização na tenacidade ao impacto de zonas fundidas, obtidas a partir de eletrodos e fluxos que resultaram em composição química semelhante à utilizada no presente trabalho, também obtiveram baixa proporção de ferrita acicular ( $42 \%$ ) e poucas alterações nos valores de energia absorvida após a normalização.

Os resultados apresentados na Figura 10 mostram que os tratamentos térmicos pós-soldagem exerceram grande influência na tenacidade ao impacto da ZTA, em todas as temperaturas ensaiadas. Observa-se que, para baixas temperaturas, o tratamento térmico a $600^{\circ} \mathrm{C}$ exerceu maior influência na tenacidade ao impacto, aumentando em $58 \mathrm{~J}$ e $52 \mathrm{~J}$ a energia absorvida nas temperaturas de $-50^{\circ} \mathrm{C}$

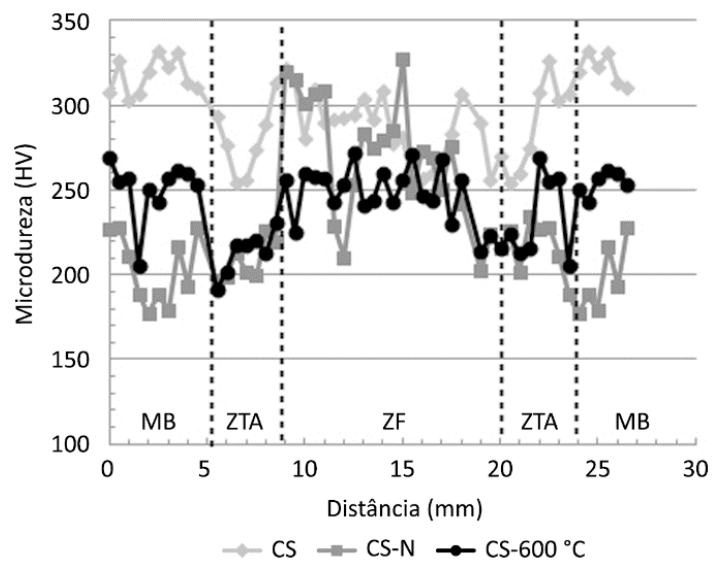

Figura 7. Perfis de microdureza do passe de acabamento. MB: Metal Base; ZTA: Zona Termicamente Afetada; ZF: Zona Fundida; CS: Como Soldado; CS-N: Como Soldado e Normalizado; CS- $600{ }^{\circ} \mathrm{C}$ : Como soldado submetido a $600{ }^{\circ} \mathrm{C}$.

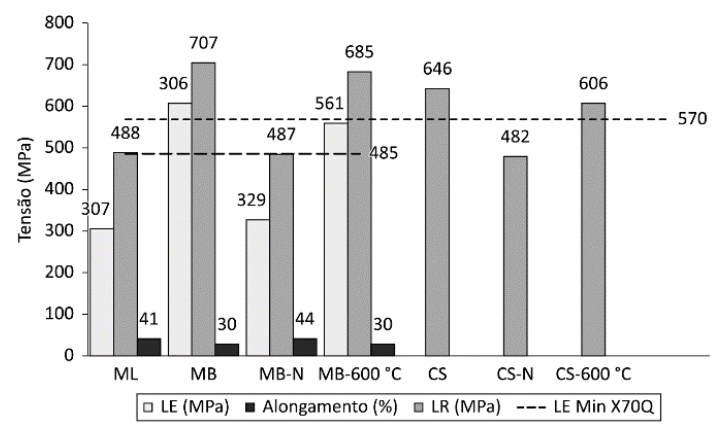

Figura 8. Resultados dos ensaios de tração nas condições analisadas.

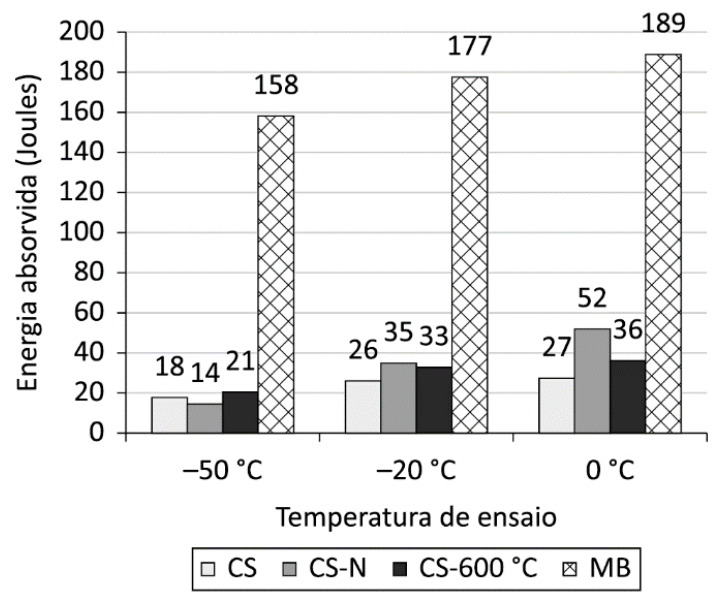

Figura 9. Energia absorvida em função da temperatura em ensaios de impacto para o material soldado com entalhe na zona fundida, nas condições CS, CS-N e $\mathrm{CS}-600^{\circ} \mathrm{C}$, além do metal base. 


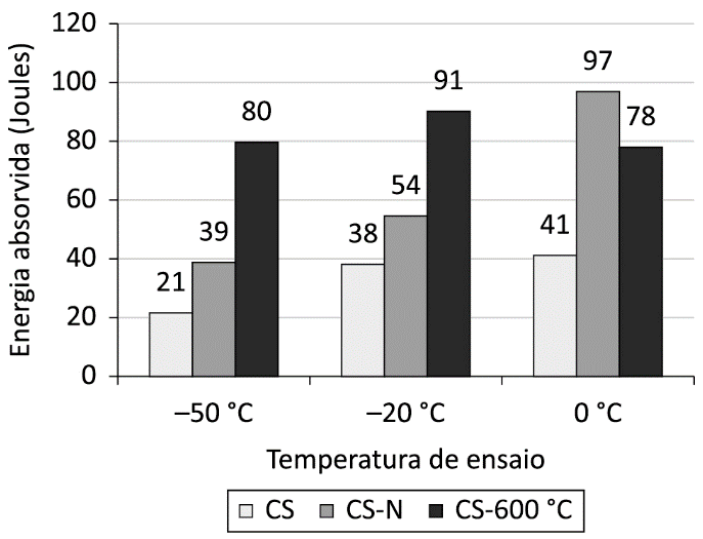

Figura 10. Energia absorvida em função da temperatura de ensaios de impacto para o material soldado com entalhe na zona termicamente afetada, nas condições CS, CS-N e CS- $600{ }^{\circ} \mathrm{C}$.

e $-20^{\circ} \mathrm{C}$, respectivamente. Esses dados corroboram a hipótese de que o tratamento térmico aplicado (CS-600 $0^{\circ} \mathrm{C}$ ) reduziu a proporção de constituinte $\mathrm{M}-\mathrm{A}$, com reflexos na maior tenacidade ao impacto devido à redução de zonas de fragilidade localizada. Na temperatura igual a $0{ }^{\circ} \mathrm{C}$, o tratamento térmico de normalização foi o que apresentou maior mudança na energia absorvida em relação ao material como soldado (56 J), mas nota-se que o tratamento térmico a $600^{\circ} \mathrm{C}$ também aumentou muito a tenacidade ao impacto (39 J).

\section{Conclusões}

Os resultados obtidos nos ensaios mecânicos e caracterização estrutural das juntas soldadas e tratadas termicamente a $920^{\circ} \mathrm{C}$ e a $600^{\circ} \mathrm{C}$ conduziram às seguintes conclusões:

- As juntas soldadas por SMAW atingiram os requisitos mínimos especificados de limite de resistência para o grau X70Q;

- $\mathrm{O}$ ataque com reagente Le Pera mostrou-se insuficiente para identificação dos constituintes M-A em microscopia óptica. No entanto, com a utilização de MEV e microdureza, foi possível distinguir os constituintes M-A de agregados ferrita-carbonetos;

- Os tratamentos térmicos de normalização $\left(920^{\circ} \mathrm{C}\right)$ e na temperatura de $600^{\circ} \mathrm{C}$ exerceram pouca influência na tenacidade ao impacto da zona fundida, resultados atribuídos à formação de constituinte M-A-B após a normalização e à pequena fração de ferrita acicular no metal de solda;

- O tratamento térmico a $600{ }^{\circ} \mathrm{C}$ mostrou-se eficiente para o aumento da tenacidade ao impacto da ZTA;

- Os resultados obtidos no ensaio de tração mostraram que não foi possível manter o limite de resistência para o grau $X 70 Q$ com a realização de tratamento térmico de normalização pós-soldagem, pois o limite de resistência obtido foi equivalente ao grau X46;

- O tratamento térmico pós-soldagem a $600{ }^{\circ} \mathrm{C}$ mostrou-se viável para aumentar a tenacidade ao impacto da ZTA e ainda manteve o limite de resistência especificado para o grau X70Q.

\section{Agradecimentos}

À Coordenação de Aperfeiçoamento de Pessoal de Nível Superior (CAPES).

\section{Referências}

[1] American Petroleum Institute - API. API 5L: Petroleum and natural gas industries - steel pipe for pipeline transportation. 45 ed. Washington: API; 2012.
[2] Silva, RF. Caracterização da Zona Termicamente Afetada de Aço Produzido via Resfriamento Acelerado [dissertação de mestrado]. Belo Horizonte: UFMG; 2010. 
Avaliação da Influência de Tratamentos Térmicos Pós-Soldagem Sobre a Microestrutura e Propriedades Mecânicas de Juntas de um Aço API 5 L X70Q

[3] Batista, GZ. Curvamento por indução de tubo da Classe API 5L X80 [dissertação de mestrado]. Rio de Janeiro: PUC; 2005

[4] Batista GZ, Souza LFG, BOTTI. S., RIOS PR. Estudo da correlação microestrutura-propriedades mecânicas de aço da Classe API X80. In: Associação Brasileira de Metalurgia e Materiais. $58^{\circ}$ Congresso Anual da ABM; 2003 Julho 21- 24; Rio de Janeiro. Rio de Janeiro: Associação Brasileira de Metalurgia e Materiais; 2003. p. 2957-2966

[5] Trindade VB, Payão FJC, Guimarães AS, Paranhos RPR. Normalizing heat treatment on the mechanical behavior of low-alloy steel weld metals. Journal of the Brazilian Society of Mechanical Sciences and Engineering. 2004;26(1):62-66. http://dx.doi. org/10.1590/S1678-58782004000100011.

[6] American Petroleum Institute - API. API 1104: Welding of pipelines and related facilities. 20 ed. Washington: API; 2008.

[7] American Society for Testing and Materials - ASTM. ASTM E562: Standard test method for determining volume fraction by systematic manual point count. West Conshohocken: ASTM; 2011.

[8] American Society for Testing and Materials - ASTM. ASTM A370: Standard test methods and definitions for mechanical testing of steel products. West Conshohocken: ASTM; 2014

[9] Laitinen R. Improvement of weld HAZ toughness at low heat input by controlling the distribution of M-A constituents [tese de doutorado]. Oulu: Universidade de Oulu; 2006.

[10] Hrivnak I, Matsuda F, Li Z, Ikeuchi K, Okada H. Investigation of metallography and behaviour of $\mathrm{M}-\mathrm{A}$ constituent in weld HAZ of HSLA steels. Transactions of Japan Welding Institute. 1992;21(2):101-110.

[11] Colpaert H. Metalografia dos produtos siderúrgicos comuns. 4 ed. São Paulo: Edgard Blucher; 2008. Revisão técnica André Luiz V. da Costa e Silva. 